\title{
Study of the Effects of Simple Exercise With or Without Physiotherapy on Prevention of Deep Vein Thrombosis Among Postmenopausal Women Requiring Coronary Artery Bypass Graft Surgery
}

\author{
Khosrow Hashemzadeh $^{1}{ }^{\circledR}$, Marjan Dehdilani' ${ }^{2}$, Mehdi Khanbabayi Gol ${ }^{*} \oplus$
}

\begin{abstract}
Objectives: Menopause is one of the risk factors for deep vein thrombosis (DVT) that may increase its likelihood after coronary artery bypass graft surgery (CABG). Hence, it is essentially advised to prevent DVT. In this regard, the purpose of this study was to investigate the effects of simple exercise with and without physiotherapy on DVT prevention in postmenopausal women requiring CABG.

Materials and Methods: This quasi-experimental study was carried out on 34 patients in Tabriz Shahid Madani hospital from 1 March to the end of July 2019. It is noteworthy that participants were selected based on a random sampling method. The experimental group, namely, the exercise group $(n=17)$ did cardiovascular exercises for 40 minutes the day before the surgery. However, the other group received physiotherapy for each leg for 15 minutes in addition to cardiovascular exercise. Then, DVT diagnosis blood tests, clinical examinations, and Doppler sonography were performed and recorded in all participants' portfolios. The obtained data were analyzed using SPSS software, and the SPSS tests included Kolmogorov-Smirnov, paired $t$ test, and independent t-test at the significance level of 0.05 .

Results: The results of intra-group DVT and blood tests before and after the intervention revealed a statistically significant difference in terms of complete blood count, hemoglobin, hematocrit $(P \leq 0.05)$. However, no statistically significant differences were reported considering the other variables $(P \geq 0.11)$. Finally, in the case of inter-group variations, a comparison of the results of the two groups represented no statistically significant difference in any of the studied variables $(P \geq 0.15)$.

Conclusions: In general, a light exercise session either with or without physiotherapy did not have any positive effects on DVT prevention in postmenopausal women in need of CABG.

Keywords: DVT, CABG, Prevention, Exercise, Physiotherapy
\end{abstract}

\section{Introduction}

Each year, cardiovascular diseases kill a vast number of people around the world. According to the reports of the World Health Organization, with regard to chronic diseases, chronic immobility causes $70 \%$ of deaths and $21 \%$ of deaths are due to coronary artery disease (CAD) which is known as the leading cause of death (1). Various biological factors have been identified for coronary heart disease, including abnormal blood lipids, elevated bad cholesterol (low-density lipoprotein cholesterol) levels, hypertension, the lack of physical activity or exercise, overweight and obesity, weight gain, ageing, family history, smoking, and menopause (There is a positive relationship between heart disease and menopause) in women $(2,3)$.

Menopause increases the risk of CAD among postmenopausal women due to a decline in sex steroid hormones and an increase in body fat, especially abdominal fat (4). In addition, there may be other mechanisms associated with heart disease in postmenopausal women (sedentary and inactive) that need further investigation (3). Coronary artery bypass graft surgery (CABG) is the main treatment when $\mathrm{CAD}$ is more severe (5). Nevertheless, CABG has postoperative complications, along with its benefits for the patient. One of the most dangerous complications is deep vein thrombosis (DVT) with a prevalence of approximately $70 \%-80 \%$ after CABG. In fact, it is one of the major causes of postoperative mortality $(6,7)$. Hence, given the high prevalence of this complication, preventive measures are necessary for these individuals.

Non-pharmacological measures such as light exercise and physiotherapy have been suggested as preventive measures for DVT in addition to preoperative medication (8). However, no similar studies have so far focused on postmenopausal women. It should be noted that menopause is a risk factor for $\mathrm{CAD}$ and $\mathrm{CABG}$ is a 
Key Messages

- Menopause is associated with an increased risk of deep vein thrombosis.

- DVT is dangerous and deadly after coronary artery bypass graft surgery.

- An exercise session with/without physiotherapy before CABG cannot prevent DVT.

common treatment for these diseases. In addition, DVT is one of the undesirable complications after surgery and menopause is a risk factor for DVT (9). Further, DVT may occur after postmenopausal CABG more than other periods. Therefore, the present study aimed at evaluating the effects of simple exercise training with and without physiotherapy on the prevention of DVT in postmenopausal women requiring emergency cardiac surgery.

\section{Materials and Methods}

The present quasi-experimental research was conducted at Tabriz Shahid Madani Hospital (sampling, intervention, and data collection context) from March 1st to the end of July 2019. The inclusion criteria included the confirmation of menopause by a gynecologist, a minimum of six months after menopause, and a need for CABG diagnosed by a heart surgeon. Moreover, the exclusion criteria were dissatisfaction with study participation, previous DVT and family history, lower limb varicose vein disease, inability to exercise, the presence of a cardiac pacemaker, and contraindications to exercise. They were all related to the surgeon's diagnosis and opinion.

A total number of 34 females (17 in the exercise group and 17 in exercise + physiotherapy group) were selected for the study using the formula and considering a significance level of 0.05 (10). The exercise group only did the exercise while the exercise + physiotherapy group did physiotherapy in addition to exercise. First, sampling was done based on availability and purposive techniques, and then the samples were randomly divided into two groups (A and B) by a statistical consultant.

After sampling, the researchers precisely explained the aims of the study to the participants or their acquaintances and answered any potential questions related to the study. Eventually, the participants who were willing to participate in the study filled a written consent form.

All patients were admitted to the relevant ward at Shahid Madani hospital 3 days before the surgery, and routine tests, consultations, and measures were taken to prepare patients for surgery. These actions were mainly performed for all patients. It is important to note that the intervention was done the day before the surgery. The participants of the exercise group received the intervention for forty minutes under the supervision of a physical and a rehabilitation specialist at nine oclock in the morning including warming up body parts with stretching and flexion activities for an average of 5-10 minutes. Then, the main exercise program was carried out, and finally, 5-10 minutes of cooling and relaxation were allocated to the participants of each group. The main exercise program was conducted and monitored according to the recommended standards for cardiac patients such as walking on a treadmill with zero slopes, pedaling on a stationary bike, and using an ergometer. The exercise started with moderate intensity. Thus, 50\% of the maximum heart rate (HR) was considered as the target HR for patients in addition to the amount of fatigue and cardiac symptoms. During exercise, blood pressure, $\mathrm{HR}$, and electrocardiogram (ECG) were continuously monitored by a monitoring device. The researchers carefully observed the progress to check any possible ischemic changes in the ECG, dangerous arrhythmias, and an HR decline which exceeded 10 beats despite exercise, rest, and withdrawal. Moreover, any symptoms of hemodynamic abnormalities, elevated systolic blood pressure greater than 200, and diastolic greater than 110 $\mathrm{mm} \mathrm{Hg}$ were thoroughly considered during the study. In cases that any one of these problematic situations were experienced, the researchers stopped the exercise and delayed the data collection procedure until treating the complications (11).

For the group receiving exercise and physiotherapy, the intervention (exercise) was exactly the same as the other group. However, immediately 6 hours later, an expert physiotherapist, who was trained for this purpose, performed physiotherapy for lower parts of the body. The procedure of physiotherapy lasted for 15 minutes for each leg (ten and five minutes below and above the knee, respectively). The movements were painless and the focus was on vein areas (12).

Further, blood samples were obtained from participants before and after the test, and subjects were asked to sit on a chair for 20 minutes before taking blood samples. Then, four $\mathrm{mL}$ of the blood was taken from an arm vein. The specimens were prepared and sent to the laboratory of Shahid Madani hospital. This was done two times, namely, during pre-intervention and the day after the surgery. All blood samples were used for complete blood count (RBC), hemoglobin (Hgb), hematocrit (Hct), polymerase chain reaction, prothrombin time, partial thromboplastin time, international normalized ratio, D-Dimer, protein C, and protein $\mathrm{S}$ examination. Furthermore, the symptoms of DVT were checked by a specialist, and Doppler ultrasound was performed when the results of laboratory tests were in favor of the symptoms of thrombosis. All data were recorded in a researcher-made checklist based on the purpose of the study. It should be noted that the routine postoperative procedures were similar for all patients. Other body parameters including weight, height, body mass index (BMI), and body fat percentage (measured by Caliper-Pondenral Huidplooidkte-Meter) were also measured for each participant (13). The resting heart rate, resting systolic blood pressure, and resting diastolic blood 
pressure were recorded as well.

The researchers were required to adhere to ethics in research and ethical considerations similar to other studies (14-26). This included assuring research confidentiality and privacy, offering voluntary participation, conducting a free-of-charge intervention, and receiving a code of ethics from Tabriz University of Medical Sciences, and finally, enrolling in Iran's clinical trial system. The obtained data were analyzed using the Kolmogorov-Smirnov test, paired $t$ test, and independent $t$ test (the use of each test is listed in the corresponding table in the Results section) by SPSS software, version 21 . Notably, a $P$ value less than 0.05 was considered statistically significant.

\section{Results}

A number of 34 females out of 53 postmenopausal women in need of CABG entered the study and received the intervention. They were selected after meeting the inclusion and exclusion criteria and attended the study until its termination (sample dropout $=0$ ).

The mean and standard deviation of age, height, weight, and participants' BMI were calculated based on the Kolmogorov-Smirnov test and the results were 53.12 \pm 06.18 (years), $169.29 \pm 12.35(\mathrm{~cm}), 76.59 \pm 08.63(\mathrm{~kg})$, and $28.36 \pm 05.90\left(\mathrm{~kg} / \mathrm{m}^{2}\right)$, respectively. The difference between the two groups was not statistically significant in the normal distribution. The results are presented in Table 1.

Based on the results of the independent $t$ test, postintervention findings were not significantly different $(P \leq 0.129)$, the details of which are provided in Table 2 .

The results of blood tests and the DVT diagnoses of within the groups collected before and after the intervention were compared using a paired $t$ test. The results represented a statistically significant difference in terms of RBC, Hgb, and Hct $(P \leq 0.05)$. However, no significant differences were reported regarding other variables $(P \geq 0.11)$. Table 3 summarizes the intra-group results of blood tests and DVT diagnosis.

Table 1. Descriptive Information of Participants Before the Intervention

\begin{tabular}{lccc}
\hline $\begin{array}{l}\text { Study } \\
\text { Variables }\end{array}$ & $\begin{array}{c}\text { Exercise } \\
\text { Group }\end{array}$ & $\begin{array}{c}\text { Exercise + Physiotherapy } \\
\text { Group }\end{array}$ & $\boldsymbol{P}$ Value \\
\hline Age & $52.59 \pm 05.26$ & $53.89 \pm 06.55$ & $0.159^{*}$ \\
Height & $165.55 \pm 13.20$ & $171.50 \pm 10.80$ & $0.211^{*}$ \\
Weight & $77.12 \pm 05.33$ & $76.30 \pm 06.29$ & $0.209^{*}$ \\
BMl & $28.36 \pm 05.90$ & $28.36 \pm 05.90$ & $0.301^{*}$ \\
Body lipid & $09.12 \pm 01.10$ & $09.25 \pm 01.25$ & $0.309^{*}$ \\
RHR & $88.50 \pm 10.33$ & $91.01 \pm 11.20$ & $0.409^{*}$ \\
RSBP & $142.63 \pm 10.82$ & $139.71 \pm 11.25$ & $0.362^{*}$ \\
RDBP & $85.20 \pm 07.52$ & $83.91 \pm 06.95$ & $0.315^{*}$ \\
\hline
\end{tabular}

Data are shown as mean \pm standard deviation (SD).

BMI: body mass index; RHR: rest heart rate; RSBP: rest systolic blood pressure; RDBP: rest diastolic blood pressure.

* Not significant; Kolmogorov-Smirnov test was used in this regard.
The independent $t$ test results also indicated that there was no statistically significant difference in any of the studied variables $(P \geq 0.15)$. The comparative pre- and post-operative results between the groups using a paired t-test are presented in Table 4.

Eventually, no clinical examination was performed to diagnose DVT since DVT diagnostic indices did not confirm its presence after the intervention.

\section{Discussion}

The aim of this study was to scrutinize the effects of simple exercise with and without physiotherapy on the prevention of DVT among postmenopausal women requiring CABG surgery. In menopause, the risk of heart disease increases due to the disruption of hormonal balance, inactivity, and increased body fat (3). CABG is one of the most common treatments for coronary artery disease whose occurrence increases with age (27). In addition, DVT is considered as one of the most serious and fatal complications after the surgery. There are many factors contributing to this complication, the most common of which are age, menopause, and major surgeries (28). It seems that the probability of DVT development among postmenopausal women exposed to CABG is higher compared to the others. Given the increased likelihood of this occurrence, taking non-pharmacological actions, along with pharmacological measures can be considered as a preventive intervention in this respect. In this study, some actions were considered, including exercise appropriate for heart performance and physiotherapy.

Based on the findings of this study, there was a significant result regarding the decrease in $\mathrm{RBC}, \mathrm{Hgb}$, Hct levels after the surgery, which is in line with the results of similar studies (29-31). Blood loss during cardiac surgery was a normal and undeniable phenomenon.

The findings further revealed that exercise had no effect on DVT-influenced indices. In other words, these indices failed to improve these factors before and after exercise, which contradicts the results of Garcia et al (32), demonstrating an improvement in effective indices on DVT after the intervention. However, the difference between the findings of Garcia et al and the current research is related to the nature of the intervention. More precisely, unlike Garcia et al who considered regular

Table 2. A Comparative Analysis of the Findings After the Intervention

\begin{tabular}{lccc}
\hline $\begin{array}{l}\text { Study } \\
\text { Variables }\end{array}$ & $\begin{array}{c}\text { Exercise } \\
\text { Group }\end{array}$ & $\begin{array}{c}\text { Exercise + Physiotherapy } \\
\text { Group }\end{array}$ & P Value \\
\hline RHR & $91.29 \pm 11.05$ & $93.12 \pm 11.40$ & $0.129^{*}$ \\
RSBP & $140.55 \pm 10.20$ & $138.20 \pm 10.10$ & $0.300^{*}$ \\
RDBP & $87.15 \pm 07.10$ & $85.25 \pm 06.18$ & $0.296^{*}$ \\
\hline
\end{tabular}

Data are shown as mean \pm standard deviation $(\mathrm{SD})$.

RHR: rest heart rate; RSBP: rest systolic blood pressure; RDBP: rest diastolic blood pressure.

* Not significant; $t$ test was used in this regard. 
Table 3. A Comparative Analysis of the Findings of Intra-group Blood Tests and DVT Diagnoses

\begin{tabular}{|c|c|c|c|c|c|}
\hline Study Variables & Group & Before Surgery & After Surgery & $T$ Value & $P$ Value \\
\hline \multirow{2}{*}{$\begin{array}{c}\mathrm{RBC}(\mathrm{M} \pm \mathrm{SD}) \\
\text { cells/mcL }\end{array}$} & Exercise $(n=17)$ & $4.9 \pm 0.22$ & $4.0 \pm 0.15$ & -2.90 & $0.001^{*}$ \\
\hline & Exercise+ Physiotherapy $(n=17)$ & $4.80 \pm 0.30$ & $4.0 \pm 0.90$ & -2.97 & $0.001^{*}$ \\
\hline \multirow{2}{*}{$\begin{array}{l}\mathrm{Hgb}(\mathrm{M} \pm \mathrm{SD}) \\
\mathrm{g} / \mathrm{dL}\end{array}$} & Exercise $(n=17)$ & $13.25 \pm 2.50$ & $11.35 \pm 1.30$ & -1.99 & $0.005^{*}$ \\
\hline & Exercise+ Physiotherapy $(n=17)$ & $14.00 \pm 1.00$ & $12.25 \pm 2.50$ & -2.11 & $0.001^{*}$ \\
\hline \multirow{2}{*}{$\begin{array}{l}\text { Hct }(M \pm S D) \\
\%\end{array}$} & Exercise $(n=17)$ & $39.2 \pm 5.90$ & $33.11 \pm 4.77$ & -1.90 & $0.001^{*}$ \\
\hline & Exercise+ Physiotherapy $(n=17)$ & $38.50 \pm 4.95$ & $35.40 \pm 5.15$ & -1.91 & $0.001^{*}$ \\
\hline \multirow{2}{*}{$\begin{array}{l}\mathrm{PCR}(\mathrm{M} \pm \mathrm{SD}) \\
\mathrm{mg} / \mathrm{L}\end{array}$} & Exercise $(n=17)$ & $1.21 \pm 0.20$ & $1.18 \pm 0.20$ & 1.37 & 0.82 \\
\hline & Exercise+ Physiotherapy $(n=17)$ & $1.40 \pm 0.01$ & $1.35 \pm 0.12$ & 1.30 & 0.80 \\
\hline \multirow{2}{*}{$\begin{array}{l}\mathrm{PT}(\mathrm{M} \pm \mathrm{SD}) \\
\text { Time }(\mathrm{s})\end{array}$} & Exercise $(n=17)$ & $12.20 \pm 1.11$ & $12.15 \pm 0.90$ & -0.70 & 0.48 \\
\hline & Exercise+ Physiotherapy $(n=17)$ & $12.51 \pm 1.01$ & $12.00 \pm 0.88$ & -0.75 & 0.40 \\
\hline \multirow{2}{*}{$\begin{array}{l}\text { PTT }(M \pm S D) \\
\text { Time }(s)\end{array}$} & Exercise $(n=17)$ & $29.20 \pm 2.50$ & $28.14 \pm 2.01$ & -1.01 & 0.33 \\
\hline & Exercise+ Physiotherapy $(n=17)$ & $27.95 \pm 1.31$ & $27.40 \pm 2.20$ & -1.60 & 0.13 \\
\hline \multirow{2}{*}{$\begin{array}{l}\text { INR }(\mathrm{M} \pm \mathrm{SD}) \\
\text { Time }(\mathrm{s})\end{array}$} & Exercise $(n=17)$ & $1.09 \pm 0.12$ & $1.03 \pm 0.15$ & -0.71 & 0.25 \\
\hline & Exercise+ Physiotherapy $(n=17)$ & $1.07 \pm 0.10$ & $1.05 \pm 0.10$ & -1.02 & 0.33 \\
\hline \multirow{2}{*}{$\begin{array}{l}\text { D-Dimer }(\mathrm{M} \pm \mathrm{SD}) \\
\mathrm{ng} / \mathrm{mL}\end{array}$} & Exercise $(n=17)$ & $411.52 \pm 62.18$ & $409.18 \pm 60.25$ & -1.40 & 0.39 \\
\hline & Exercise+ Physiotherapy $(n=17)$ & $419.30 \pm 60.52$ & $409.15 \pm 55.90$ & -1.11 & 0.42 \\
\hline \multirow{2}{*}{$\begin{array}{l}\operatorname{Pr} C(M \pm S D) \\
\%\end{array}$} & Exercise $(n=17)$ & $92.18 \pm 12.25$ & $90.45 \pm 13.01$ & -1.01 & 0.13 \\
\hline & Exercise+ Physiotherapy $(n=17)$ & $95.19 \pm 10.60$ & $91.90 \pm 14.20$ & -1.06 & 0.11 \\
\hline \multirow{2}{*}{$\begin{array}{l}\operatorname{Pr} S(M \pm S D) \\
\%\end{array}$} & Exercise $(n=17)$ & $90.20 \pm 11.21$ & $89.90 \pm 10.85$ & -1.77 & 0.25 \\
\hline & Exercise+ Physiotherapy $(n=17)$ & $91.50 \pm 09.18$ & $90.03 \pm 10.35$ & -1.39 & 0.20 \\
\hline
\end{tabular}

Note. M: Mean; SD: Standard deviation; DVT: Deep vein thrombosis; RBC: Complete blood count; Hgb: Hemoglobin; Hct: Hematocrit; PCR: Polymerase chain reaction; PT: Prothrombin time; PTT: Partial thromboplastin time; INR: International normalized ratio; Pr C: Protein C; Pr S: Protein S.

* Significant; Paired $t$ test was used in this regard.

Table 4. A Comparative Analysis of the Findings of Blood Tests and DVT Diagnoses Between the Two Groups

\begin{tabular}{|c|c|c|c|c|c|}
\hline Study Variables & Stage of the Study & Exercise $(n=17)$ & Exercise + Physiotherapy $(n=17)$ & $T$ Value & $P$ Value \\
\hline \multirow{2}{*}{$\begin{array}{l}\mathrm{RBC}(\mathrm{M} \pm \mathrm{SD}) \\
\text { cells/mcL }\end{array}$} & Preoperative & $4.9 \pm 0.22$ & $4.80 \pm 0.30$ & 1.30 & 0.41 \\
\hline & Postoperative & $4.0 \pm 0.15$ & $4.0 \pm 0.90$ & 1.25 & 0.44 \\
\hline \multirow{2}{*}{$\begin{array}{l}\mathrm{Hgb}\left(\mathrm{M}_{ \pm} \mathrm{SD}\right) \\
\mathrm{Gr} / \mathrm{DL}\end{array}$} & Preoperative & $13.25 \pm 2.50$ & $14.00 \pm 1.00$ & 1.45 & 0.19 \\
\hline & Postoperative & $11.35 \pm 1.30$ & $12.25 \pm 2.50$ & 1.20 & 0.15 \\
\hline \multirow{2}{*}{$\begin{array}{l}\text { Hct }(M \pm S D) \\
\%\end{array}$} & Preoperative & $39.2 \pm 5.90$ & $38.50 \pm 4.95$ & 1.35 & 0.25 \\
\hline & Postoperative & $33.11 \pm 4.77$ & $35.40 \pm 5.15$ & 1.40 & 0.21 \\
\hline \multirow{2}{*}{$\begin{array}{l}\mathrm{PCR}(\mathrm{M} \pm \mathrm{SD}) \\
\mathrm{mg} / \mathrm{L}\end{array}$} & Preoperative & $1.21 \pm 0.20$ & $1.40 \pm 0.01$ & 1.87 & 0.40 \\
\hline & Postoperative & $1.18 \pm 0.20$ & $1.35 \pm 0.12$ & 1.80 & 0.44 \\
\hline \multirow{2}{*}{$\begin{array}{l}\text { PT }(M \pm S D) \\
\text { Time }(s)\end{array}$} & Preoperative & $12.20 \pm 1.11$ & $12.51 \pm 1.01$ & 0.19 & 0.35 \\
\hline & Postoperative & $12.15 \pm 0.90$ & $12.00 \pm 0.88$ & 0.21 & 0.30 \\
\hline \multirow{2}{*}{$\begin{array}{l}\text { PTT }(M \pm S D) \\
\text { Time(s) }\end{array}$} & Preoperative & $29.20 \pm 2.50$ & $27.95 \pm 1.31$ & 1.80 & 0.46 \\
\hline & Postoperative & $28.14 \pm 2.01$ & $27.40 \pm 2.20$ & 1.65 & 0.51 \\
\hline \multirow{2}{*}{$\begin{array}{l}\text { INR }(\mathrm{M} \pm \mathrm{SD}) \\
\text { Time }(\mathrm{s})\end{array}$} & Preoperative & $1.09 \pm 0.12$ & $1.07 \pm 0.10$ & 1.91 & 0.29 \\
\hline & Postoperative & $1.03 \pm 0.15$ & $1.05 \pm 0.10$ & 1.88 & 0.35 \\
\hline \multirow{2}{*}{$\begin{array}{l}\text { D-Dimer }(\mathrm{M} \pm \mathrm{SD}) \\
\mathrm{ng} / \mathrm{mL}\end{array}$} & Preoperative & $411.52 \pm 62.18$ & $419.30 \pm 60.52$ & -0.55 & 0.30 \\
\hline & Postoperative & $409.18 \pm 60.25$ & $409.15 \pm 55.90$ & -0.60 & 0.44 \\
\hline \multirow{2}{*}{$\begin{array}{l}\operatorname{Pr} C(M \pm S D) \\
\%\end{array}$} & Preoperative & $92.18 \pm 12.25$ & $95.19 \pm 10.60$ & 1.99 & 0.29 \\
\hline & Postoperative & $90.45 \pm 13.01$ & $91.90 \pm 14.20$ & 1.85 & 0.33 \\
\hline \multirow{2}{*}{$\begin{array}{l}\operatorname{Pr} S(M \pm S D) \\
\%\end{array}$} & Preoperative & $90.20 \pm 11.21$ & $91.50 \pm 09.18$ & 1.17 & 0.26 \\
\hline & Postoperative & $89.90 \pm 10.85$ & $90.03 \pm 10.35$ & 1.15 & 0.28 \\
\hline
\end{tabular}

Note. M: Mean; SD: Standard deviation; DVT: Deep vein thrombosis; RBC: Complete blood count; Hgb: Hemoglobin; Hct: Hematocrit; PCR: Polymerase chain reaction; PT: Prothrombin time; PTT: Partial thromboplastin time; INR: International normalized ratio; Pr C: Protein C; Pr S: Protein S.

* Significant; Paired $t$ test was used in this regard. 
exercise as the intervention, the researchers of this study used the exercise only for one session.

The effects of exercise on DVT prevention are undeniable although the selection of exercise for a specific group of patients and the extent of exercise application remain unknown. In another study, Zheng et al (33) examined the effects of longitudinal exercise on the coagulation status of individuals and reported favorable recovery after the intervention. Thus, they recommended the implementation of this protocol by other researchers. It is important to note that the results of the above-mentioned study differed from those of the present study.

The present study also investigated the effects of exercise accompanied by physiotherapy on DVT prevention. Generally, no intervention was observed in the prevention of DVT. In this regard, Song et al (34) reported the effectiveness of physiotherapy on factors affecting DVT. Their intervention lasted for one week and positive effects were reported on DVT prevention, the results of whom are not consistent with the findings of the present study. Moreover, their findings may be related to the type and duration of the intervention. It seems that physiotherapy with increased blood flow can reduce the risk of DVT and thus can be an effective protocol for DVT prevention if it is conducted effectively and regularly.

\section{Limitations of the Study}

Some of the limitations of this study include one-session exercise and physiotherapy before and after the surgery, the discontinuation of the exercise and physiotherapy after the surgery, and the lack of paying attention to blood transfusion.

\section{Suggestions for Future Studies}

The researchers suggest that further studies increase the number of exercise and physiotherapy sessions. In addition, encouraging patients and medical staff regarding using this method for patients can have positive effects.

\section{Conclusions}

Based on the findings, a light exercise for one session either with or without physiotherapy had no positive effect on the prevention of DVT in postmenopausal women requiring coronary artery bypass surgery.

\section{Authors' Contribution}

KH: Intervention. MD: Follow-up. MK: Study design, manuscript preparation and manuscript submit.

\section{Conflict of Interests}

Authors declare that they have no conflict of interests.

\section{Ethical Issues}

The research project was approved by the Ethics Committee of Tabriz University of Medical Sciences (ethics no. IR.TBZMED.REC.1397.1059; IRCT No: IRCT20190325043107N6).

\section{Financial Support}

This study was granted by Tabriz University of Medical Sciences.

\section{Acknowledgments}

The researchers would like to give their gratitude to the Research Center and the Health Vice-chancellor of Tabriz University of Medical Sciences for providing financial support in the study.

\section{References}

1. Musavinasab M, Ravanipour M, Pouladi S, Motamed N, Barekat M. Examining the validity and reliability of the cardiovascular disease questionnaire in measuring the empowerment of elderly patients to receive social support. Salmand: Iranian Journal of Ageing. 2016;11(2):258-269. doi:10.21859/sija-1102258

2. Golparvar $M$, Safari $H$. The association between meta-cognitive beliefs and dysfunctional attitudes among middle and aged patients with cardiovascular disease. Salmand: Iranian Journal of Ageing. 2016;11(1):52-63. doi:10.21859/sija-110152

3. Shoorideh Z, Bijeh N, Khoshraftar Yazdi N. The effect of eight weeks of aquatic aerobic training on lipid profile, Glucose, Insulin resistance and apoprotein $A$ and $B$ in overweight postmenopausal women. Iranian J Obste Gynecol Infertil. 2017;20(8):89-100. doi:10.22038/ijogi.2017.9594

4. Behjati Ardakani A, Qassemian A, Koushki M, Shakour E, Mehrez A. The effect of a resistance training course on blood pressure and nitric oxide levels in elderly women. Salmand: Iranian Journal of Ageing. 2018;13(1):16-27. doi:10.21859/sija.13.1.16

5. Velazquez EJ, Lee $\mathrm{KL}$, Jones $\mathrm{RH}$, et al. Coronary-artery bypass surgery in patients with ischemic cardiomyopathy. N Engl J Med. 2016;374(16):1511-1520. doi:10.1056/NEJMoa1602001

6. Ghazi L, Schwann TA, Engoren MC, Habib RH. Role of blood transfusion product type and amount in deep vein thrombosis after cardiac surgery. Thromb Res. 2015;136(6):1204-1210. doi:10.1016/j.thromres.2015.10.041

7. Mirhosseini SJ, Forouzannia SK, Mostafavi Pour Manshadi SM, AliHasan-Al-Saegh S, Naderi N, Sanatkar M. Comparison of aspirin plus heparin with heparin alone on asymptomatic perioperative deep vein thrombosis in candidates for elective off-pump coronary artery bypass graft: a randomized clinical trial. Cardiol J. 2013;20(2):139-143. doi:10.5603/cj.2013.0026

8. Hillegass E, Puthoff M, Frese EM, Thigpen M, Sobush DC, Auten B. Role of physical therapists in the management of individuals at risk for or diagnosed with venous thromboembolism: evidencebased clinical practice guideline. Phys Ther. 2016;96(2):143-166. doi:10.2522/ptj.20150264

9. Canonico M, Plu-Bureau G, O'Sullivan MJ, et al. Age at menopause, reproductive history, and venous thromboembolism risk among postmenopausal women: the Women's Health Initiative Hormone Therapy clinical trials. Menopause. 2014;21(3):214220. doi:10.1097/GME.0b013e31829752e0

10. Kahn SR, Azoulay L, Hirsch A, Haber M, Strulovitch C, Shrier I. Effect of graduated elastic compression stockings on leg symptoms and signs during exercise in patients with deep venous thrombosis: a randomized cross-over trial. J Thromb Haemost. 2003;1(3):494499. doi:10.1046/j.1538-7836.2003.00092.x

11. American Association of Cardiovascular and Pulmonary Rehabilitation (AACVPR). Guidelines for Cardiac Rehabilitation and Secondary Prevention Programs. 5th ed. Human Kinetics; 2013.

12. Koorosh Fard N, Alizadeh MH, Rajabi R, Shirzad E. Effect of feedback corrective exercise on knee valgus and electromyographic activity of lower limb muscles in single leg squat. Rehabilitation. 2015;16(2):138-147.

13. Ghanbari A, Tayebi SM. The effect of a single session of eccentric resistance exercise on some parameters of white blood cells. Ann Appl Sport Sci. 2013;1(4):17-26.

14. Hosseinzadeh $\mathrm{H}$, Golzari S, Abravesh $\mathrm{M}$, et al. Effect of low dose dopamine on early graft function in living unrelated kidney donors. Urol J. 2012;9(1):389-396. doi:10.22037/uj.v9i1.1387

15. Farhoudi M, Ayromlou H, Bazzazi AM, et al. Time frequency of Guillain-Barre syndrome in northwest of Iran. Life Science Journal. 2013;10(1):223-225. doi: 10.7537/marslsj100113.34 
16. Movassaghi R, Peirovifar A, Aghamohammadi D, Mohammadipour Anvari $\mathrm{H}$, Golzari SE, Kourehpaz Z. premedication with single dose of acetazolamide for the control of referral shoulder pain after laparoscopic cholecystectomy. Anesth Pain Med. 2015;5(6):e29366. doi:10.5812/aapm.29366

17. Rasooli S, Moslemi F. Effects of varying doses of spinal $0.25 \%$ hyperbaric bupivacaine on visceral pain in cesarean section. J Med Sci. 2007;7(1):136-140. doi:10.3923/jms.2007.136.140

18. Rasooli S, Parish M, Mahmoodpoor A, Moslemi F, Sanaie S, Faghfuri S. The effect of intramuscular ephedrine in prevention of hypotension due to propofol. Pak J Med Sci. 2007;23(6):893-897.

19. Ziyadi S, Bastani P, Homayouni A, Mohammad-AlizadehCharandabi S, Mallah F. Probiotics and usage in urinary tract infection. In: Watson RR, Preedy VR, eds. Probiotics, Prebiotics, and Synbiotics: Bioactive Foods in Health Promotion. London: Elsevier Inc; 2016:827-830. doi:10.1016/B978-0-12-8021897.00063-0

20. Mallah F, Nazari F, Navali N, Hajipour B. Comparison of direct visual inspection (DVI) with pap smear in diagnosis of precancerous lesion of cervix. Life Sci J. 2012;9(4):2556-2560.

21. Mallah F, Tasbihi P, Navali N, Azadi A. Urinary incontinence during pregnancy and postpartum incidence, severity and risk factors in Alzahra and Taleqani hospitals in Tabriz, Iran, 2011-2012. Int J Women's Health Reprod Sci. 2014;2(3):178-185. doi:10.15296/ ijwhr.2014.26

22. Bastani P, Shoari N, Hajebrahimi S, Mallah F, Azadi A. Comparison of performing and not-performing the prophylactic surgery for urinary incontinence in advanced pelvic organ prolapse. Int J Women's Health Reprod Sci. 2014;2(5):311-315. doi:10.15296/ ijwhr.2014.51

23. Navali N, Azhary Shokoufe L, Mallah F, Bastani P, Mashrabi O. Comparing therapeutic effects of Metformin and Pioglitazone in Polycystic ovary syndrome (PCOS). Pak J Med Sci. 2012;28(3):390394.

24. Mobaraki N, Kahnamouei-Aghdam F, Amani F, Mahami S. Comparing the effectiveness of intravenous oxytocin versus rectal misoprostol in the management of third-stage of labour after second-trimester abortion. Int J Women's Health Reprod Sci. 2016;4(4):181-184. doi:10.15296/ijwhr.2016.40

25. Homayouni Rad A, Azizi A, Darghahi R, et al. Development of synbiotic milk chocolate enriched with Lactobacillus paracasei, D-tagatose and galactooligosaccharide. Appl Food Biotechnol. 2018;5(2):59-68. doi:10.22037/afb.v5i2.19955

26. Mobaraki N, Yousefian M, Seifi S, Sakaki M. A randomized controlled trial comparing use of enthonox with pethidine for pain relief in primigravid women during the active phase of labor. Anesth Pain Med. 2016;6(4):e37420. doi:10.5812/aapm.37420

27. Whalley B, Thompson DR, Taylor RS. Psychological interventions for coronary heart disease: cochrane systematic review and metaanalysis. Int J Behav Med. 2014;21(1):109-121. doi:10.1007/ s12529-012-9282-x

28. Ho KM, Bham E, Pavey W. Incidence of venous thromboembolism and benefits and risks of thromboprophylaxis after cardiac surgery: a systematic review and meta-analysis. J Am Heart Assoc. 2015;4(10):e002652. doi:10.1161/jaha.115.002652

29. Scrascia G, Rotunno C, Nanna D, et al. Pump blood processing, salvage and re-transfusion improves hemoglobin levels after coronary artery bypass grafting, but affects coagulative and fibrinolytic systems. Perfusion. 2012;27(4):270-277. doi:10.1177/0267659112442236

30. Kilic A, Whitman GJ. Blood transfusions in cardiac surgery: indications, risks, and conservation strategies. Ann Thorac Surg. 2014;97(2):726-734. doi:10.1016/j.athoracsur.2013.08.016

31. Gross I, Seifert B, Hofmann A, Spahn DR. Patient blood management in cardiac surgery results in fewer transfusions and better outcome. Transfusion. 2015;55(5):1075-1081. doi:10.1111/ trf. 12946

32. Garcia CB, Seguro LP, Perandini LA, et al. Acute physical exercise is safe in patients with primary antiphospholipid syndrome with exclusive venous thrombosis and under oral anticoagulation with warfarin. Rheumatol Int. 2014;34(12):1737-1741. doi:10.1007/ s00296-014-3038-7

33. Zheng G, Zheng Y, Xiong Z, Ye B, Tao J, Chen L. Effect of Baduanjin exercise on cognitive function in patients with post-stroke cognitive impairment: study protocol for a randomised controlled trial. BMJ Open. 2018;8(6):e020954. doi:10.1136/bmjopen-2017-020954

34. Song Y, Wu W, Jia M. Effects of physiotherapy in the prevention of lower extremity deep venous thrombosis in patients with colorectal tumors after operation. Mod Clin Nurs. 2017;16(5):43-46.

(C) 2021 The Author(s); This is an open-access article distributed under the terms of the Creative Commons Attribution License (http:// creativecommons.org/licenses/by/4.0), which permits unrestricted use, distribution, and reproduction in any medium, provided the original work is properly cited. 